\title{
Long term patterns in the late summer trophic niche of the invasive pumpkinseed sunfish Lepomis gibbosus
}

\author{
C. Gkenas ${ }^{1, \star}$, M.F. Magalhães ${ }^{2}$, J. Cucherousset ${ }^{3}$, I. Domingos ${ }^{1}$ and F. Ribeiro ${ }^{1}$ \\ ${ }^{1}$ MARE, Centro de Ciências do Mar e do Ambiente, Faculdade de Ciências, Universidade de Lisboa, Campo Grande, $1749-016$ Lisboa, \\ Portugal \\ 2 CE3C, Centro de Ecologia, Evolução e Alterações Ambientais, Faculdade de Ciências, Universidade de Lisboa, 1749-106 Lisboa, Portugal \\ 3 CNRS, Université Toulouse III Paul Sabatier, ENFA; UMR5174 EDB (Laboratoire Évolution \& Diversité Biologique), 118 route \\ de Narbonne, 31062 Toulouse, France
}

Received December 1, 2015 - Revised January 22, 2016 - Accepted February 8, 2016

\begin{abstract}
Quantifying the trophic dynamics of invasive species in novel habitats is important for predicting the success of potential invaders and evaluating their ecological effects. The North American pumpkinseed sunfish Lepomis gibbosus is a successful invader in Europe, where it has caused negative ecological effects primarily through trophic interactions. Here, we quantified variations in the late summer trophic niche of pumpkinseed during establishment and integration in the mainstem of the Guadiana river, using stomach content analyses over a period of 40 years. Pumpkinseed showed a shift from trophic specialization during establishment to trophic generalism during integration. These results were concomitant with an increase in diet breadth that was accompanied by higher individual diet specialization particularly in large individuals. Irrespective of their drivers, these changes in trophic niche suggest that the potential ecological effects of pumpkinseed on recipient ecosystems can vary temporally along the invasion process.
\end{abstract}

Key-words: invasive species / trophic niche / diet shift / diet breadth / individual diet specialization

\begin{abstract}
Résumé - Tendances à long terme de la niche trophique estivale de la perche soleil Lepomis gibbosus invasive. La quantification de la dynamique trophique des espèces envahissantes dans leur aire d'introduction est importante pour prédire leur succès d'invasion et évaluer leurs potentiels effets écologiques. La perche soleil - Lepomis gibbosus - est une espèce originaire d'Amérique du Nord qui a été largement introduite en Europe où elle induit des effets écologiques négatifs principalement par des interactions trophiques. Dans cette étude, nous avons quantifié les variations de niche trophique de la perche soleil en fin d'été pendant les phases d'établissement et d'intégration dans le cours principal de la rivière Guadiana (Portugal) en comparant des contenus stomacaux sur une période de 40 ans. Nos résultats ont permis de démontrer que la perche soleil a modifié son régime alimentaire durant cette période en passant d'un régime spécialiste pendant la phase d'établissement à un régime généraliste pendant la phase d'intégration. En parallèle, nous avons également observé une augmentation de la taille de la niche trophique de la population qui était accompagnée d'une augmentation de la spécialisation trophique individuelle, notamment chez les individus les plus grands. Indépendamment des causes induisant ces changements de niche trophique, nos résultats suggèrent donc que les effets écologiques potentiels de la perche soleil sur les écosystèmes aquatiques peuvent varier pendant le processus d'invasion biologique.
\end{abstract}

Mots-clés : espèce envahissante / niche trophique / régime alimentaire / spécialisation trophique individuelle

Understanding the trophic dynamics of invasive species is crucial, as it can yield insights about the mechanisms of invasion success and the potential impacts of established invaders. The impact of an invasive species does not necessarily remain constant over the course of invasion and changes in competition and resource availability may increase or attenuate the impact of invaders on the recipient ecosystem (Strayer et al., 2006; Strayer, 2012). For instance, increases in trophic niche

^ Corresponding author: chrisgenas@gmail.com size may enhance invasion success (Tilberg et al., 2007), as the ability of invaders to exploit larger ranges of food resources may have positive effects on their dispersal and population dynamics (Kolar and Lodge, 2001; Vázquez, 2006). However, this is likely to affect a greater proportion of the native recipient community, either by promoting shifts towards use of unexploited resources (Grey and Jackson, 2012) or by increasing overlap in niche space of individual species (Shea and Chesson, 2002) and thus resulting in increased interspecific competition. Conversely, reductions in trophic niche size of 
invasive species may lead to trophic divergence from natives, which would facilitate the invader's integration into the community and their coexistence with native recipient community (Tran et al., 2015). Therefore, quantifying the temporal patterns in trophic niche of invasive species is critical for understanding whether the consequences of the invasion on recipient communities and ecosystems may change over time.

Here we focused on variations in the trophic niche of pumpkinseed sunfish Lepomis gibbosus during its invasion of the mainstem of the Guadiana river (Portugal). Recognized as one of the most invasive fish in Europe (Fox and Copp, 2014), pumpkinseed were introduced about 40 years ago to the Western Iberian Peninsula, becoming a major, ecologically damaging invader (García-Berthou and Moreno-Amich, 2000). Trophic plasticity is common among introduced pumpkinseed populations (Bhagat et al., 2011) and has been associated with its local success and the decline of native fish and prey diversity (Almeida et al., 2009). However, there is scarce evidence of diet variation over the invasion process making it difficult to evaluate whether ecological effects of pumpkinseed may change over time. The specific objectives of this study were (i) to quantify the temporal variations in the trophic niche of pumpkinseed and (ii) to determine whether trophic niche size changed over the invasion process.

Historical and contemporary dietary data were combined, covering the establishment (1985) and integration (2003 and 2013) stages of pumpkinseed invasion in the Guadiana river (Western Iberian Peninsula). During establishment, sampling was conducted at two neighboring sites in the mainstem of the Guadiana river $\left(38^{\circ} 1^{\prime} 38^{\prime \prime} \mathrm{N} ; 7^{\circ} 38^{\prime} 38^{\prime \prime} \mathrm{W}\right)$, and during the integration stage, we sampled at the proximate center between the two first sites. Riverine habitats were similar among sites, with local conditions being described in detail in Domingos (1986) and Ribeiro et al. (2007). Although native barbels (Luciobarbus spp.) likely dominated the fish assemblages over the study period, pumpkinseed has become increasingly widespread and locally abundant (Godinho et al., 1997a; Ribeiro and Collares-Pereira, 2010).

Each year, sampling was conducted late in summer (September), when prey availability is generally low and dietary plasticity may play a major role in shaping both interand intra-specific relationships in Iberian fish assemblages (Magalhães, 1993). At each 200-m site, pumpkinseed were sampled by electrofishing in all available habitats and immediately frozen. In the laboratory, individuals were measured for standard length (SL, mm), and stomach contents were analyzed under a binocular microscope. Prior to analysis, stomachs were screened for fullness, and empty stomachs were excluded from subsequent analyses. Prey items were identified to the lowest possible taxonomic level and counted. Since previous studies have reported marked variation in diet throughout ontogeny (Godinho et al., 1997b), we conducted separate analyses for small (30-60 mm SL) and large (61-90 mm SL) individuals, with the former generally being immature (Ribeiro and Collares-Pereira, 2010). Prey were grouped into categories, based on their taxonomic linkage, percentage of occurrence and relative abundance in the diet, so that each category contributed $>1 \%$ to the total prey items in at least one year and for one of the size classes.
Interannual variations in prey relative abundance in the diet were analyzed using non-metric multidimensional scaling (NMDS) and the Bray-Curtis dissimilarity index (Clarke and Gorley, 2006). Ordination was interpreted in ecological terms for stress values $<0.2$. Prior to analysis, data were squareroot transformed to reduce the influence of abundant prey and to overcome the unity-sum constraint, and then submitted to Wisconsin double standardization to improve the gradient detection of the Bray-Curtis dissimilarity index (Clarke and Gorley, 2006). Analysis of similarity (ANOSIM) was used to assess differences in diet between years with overall significance level corrected for multiple testing using the Bonferroni sequential correction. Similarity Percentage (SIMPER) analysis was used to identify prey categories with the highest contribution to diet dissimilarity. Prey categories were listed in decreasing order by their mean contribution to the total average dissimilarity, with a cut-off at $50 \%$ of cumulative average dissimilarity (Clarke and Gorley, 2006). Population diet breadth was determined for each year using the Shannon-Wiener in$\operatorname{dex}(H$; Levins, 1968), which is maximized when the population uses more prey more evenly (Colwell and Futuyama, 1971). Likewise, the degree of individual diet specialization was determined using the index of individual specialization (IS; Bolnick et al., 2002), which declines towards zero when individuals use smaller subsets of the population diet and equals 1 when all individuals consume the full set of population diet. Estimates for both indices were obtained using bootstrapped $95 \%$ confidence intervals (1000 permutations). All analyses were conducted using R (v3.0.1, R Development Core Team, 2014) and the Primer software v6.

A total of 62 stomachs and 5839 prey items were analyzed. Percentage of occurrence data indicated that chironomids were the most frequent encountered prey, with trichoptera, hemipterans and ephemeropterans also present, though in differing frequencies between them (Table 1). Copepods and cladocerans were also taken frequently by L. gibbosus, being highly apparent in 2003 (Table 1). The relative abundance of chironomids was high in the diet of pumpkinseed in 1985 and 2013 (Table 1). However, in 2013, hemipterans were also abundant in the diet of both size classes and ephemeropterans in the diet of large individuals. Copepods dominated the diet of pumpkinseed in 2003 but were seldom consumed in the other years. Cladocerans were important only in the diet of small individuals in 1985 and 2003 (Table 1).

Diet composition varied significantly among years, with 2003 being significantly dissimilar from 1985 and 2013 (Figure 1). Dissimilarity in diet among years for both size classes resulted from variation in the numeric frequency of several prey categories, with chironomids having the most consistent contribution (Table 2). Dissimilarity in the diet of small individuals between 2003 and both 1985 and 2013 reflected increases in the consumption of copepods and cladocerans. Copepods were also important in differentiating the diet of large individuals between 1985 and 2013, with less chironomids and more hemipterans and ephemeropterans being consumed through time. Similar patterns were found for diet dissimilarity between 2003 and 2013 in large individuals with the decrease in the proportions of copepods and chironomids and the increase of ephemeropterans (Table 2). 
Table 1. Variation in the numeric frequency $(\%)$ and percentage of occurrence (\%, in parentheses) of prey categories consumed by small (30-60 mm SL) and large (61-90 mm SL) pumpkinseed Lepomis gibbosus during the establishment (1985) and integration (2003 and 2013) stages of the invasion in the mainstem of the Guadiana river (Portugal). Prey categories with numeric frequencies $>20 \%$ are highlighted in bold.

\begin{tabular}{|c|c|c|c|c|c|c|c|}
\hline & \multicolumn{2}{|c|}{1985} & \multicolumn{2}{|c|}{2003} & \multicolumn{2}{|c|}{2013} & Overall \\
\hline $\begin{array}{l}\text { Size range } \\
\text { (SL, } \mathrm{mm} \text { ) }\end{array}$ & $\begin{array}{c}\text { Small fish } \\
(30-60)\end{array}$ & $\begin{array}{c}\text { Large fish } \\
(61-90)\end{array}$ & $\begin{array}{l}\text { Small fish } \\
(30-60)\end{array}$ & $\begin{array}{l}\text { Large fish } \\
(61-90)\end{array}$ & $\begin{array}{l}\text { Small fish } \\
(30-60)\end{array}$ & $\begin{array}{l}\text { Large fish } \\
(61-90)\end{array}$ & \\
\hline Chironomidae & $\mathbf{5 1 . 0}(95.7)$ & 93.9 (100.0) & $4.4(50.0)$ & $12.4(57.1)$ & $\mathbf{5 4 . 5}(100.0)$ & $41.7(100.0)$ & $38.7(83.1)$ \\
\hline Cladocera & $29.7(26.1)$ & $0.1(20.0)$ & $\mathbf{3 8 . 3}(100.0)$ & $12.6(100.0)$ & $2.7(33.3)$ & & $\mathbf{2 0 . 0}(44.1)$ \\
\hline Trichoptera & $6.6(73.9)$ & $1.3(80.0)$ & & $1.6(57.1)$ & $1.8(16.7)$ & $0.4(14.3)$ & $2.9(45.8)$ \\
\hline Hemiptera & $4.8(30.4)$ & $1.4(80.0)$ & $9.4(30.0)$ & $7.0(71.4)$ & $23.2(100.0)$ & $26.8(100.0)$ & $7.7(54.2)$ \\
\hline Copepoda & $4.1(21.7)$ & & $45.2(100.0)$ & $64.8(100.0)$ & $8.9(50.0)$ & $0.2(14.3)$ & $25.6(44.1)$ \\
\hline Ostracoda & $1.4(34.8)$ & $0.8(80.0)$ & $0.1(10.0)$ & $0.1(14.3)$ & & & $0.6(23.7)$ \\
\hline Hydracarina & $1.0(8.7)$ & & & & $1.0(16.7)$ & & $0.3(5.1)$ \\
\hline Ephemeroptera & $0.6(34.8)$ & $0.2(20.0)$ & & $0.4(28.6)$ & $4.5(33.3)$ & $30.6(100.0)$ & $2.8(33.9)$ \\
\hline Mollusca & $0.4(21.7)$ & $1.3(40.0)$ & $1.6(60.0)$ & & & & $0.6(22.0)$ \\
\hline Other prey & $0.3(26.1)$ & $0.9(80.0)$ & $0.9(50.0)$ & $1.1(85.7)$ & $3.4(50.0)$ & $0.3(14.3)$ & $0.8(42.4)$ \\
\hline Total fish & 21 & 7 & 10 & 9 & 7 & 8 & 62 \\
\hline
\end{tabular}

Table 2. Results of ANOSIM and SIMPER analyses showing prey categories with the highest contribution (\%) to between-year average dissimilarity (AvD) in the diet of small (30-60 mm SL) and large (61-90 mm SL) pumpkinseed during the establishment (1985) and integration stages (2003 and 2013) of the invasion in the mainstem of the Guadiana river (Portugal). Rank order of contribution is represented in parentheses.

\begin{tabular}{|l|c|c|c|c|c|c|c|}
\hline & AvD & Copepoda & Chironomidae & Cladocera & Hemiptera & Ephemeroptera & Trichoptera \\
\hline Between years & & & & & & & \\
Small fish $(R=0.578 ; P<0.001)$ & & & & & & \\
1985 vs. $2003(R=0.665 ; P<0.001)$ & 77.40 & $24.14(1)$ & $19.86(3)$ & $22.03(2)$ & & & \\
1985 vs. $2013(R=0.348 ; P=0.005)$ & 61.18 & & $21.75(1)$ & & $18.09(2)$ & & \\
2003 vs. $2013(R=0.843 ; P=0.002)$ & 72.86 & $26.44(2)$ & & $27.31(1)$ & & & \\
\hline Large fish $(R=0.779 ; P<0.001)$ & & & & & & \\
1985 vs. $2003(R=0.687 ; P=0.003)$ & 66.24 & $25.42(1)$ & $25.36(2)$ & & & \\
1985 vs. $2013(R=0.995 ; P<0.001)$ & 53.60 & & $20.57(2)$ & & $15.83(3)$ & $28.62(1)$ & \\
2003 vs. $2013(R=0.796 ; P=0.002)$ & 68.13 & $25.06(1)$ & $14.77(3)$ & & & $20.76(2)$ & \\
\hline
\end{tabular}

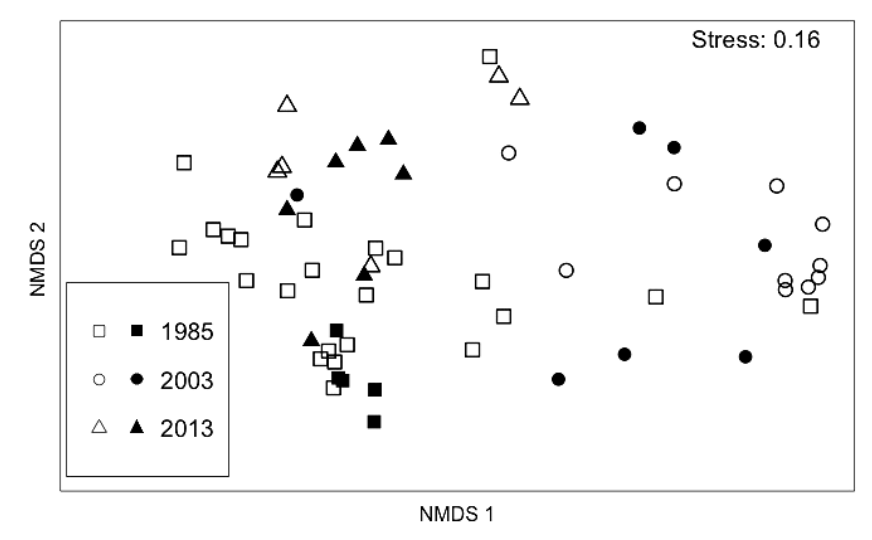

Fig. 1. Non-metric multidimensional scaling (NMDS) ordination comparing the diet of small (open symbols) and large (black symbols) pumpkinseed Lepomis gibbosus during the establishment (1985) and integration stages (2003 and 2013) of the invasion in the mainstem of the Guadiana river (Portugal).

Population diet breadth was similar between 2003 and 2013 for small and large individuals (Figure 2a), but was much narrower in 1985 particularly in large individuals. Individual diet specialization of large individuals was lower in 1985 than in 2003 and 2013 (Figure 2b). Conversely, individual diet specialization showed no changes over time in small individuals.

Our results highlighted that the late summer trophic niche of pumpkinseed varied over the invasion of our study site in the maistem of the Guadiana river. Besides shifts in staple prey, trophic niche size increased during the integration stage. These long-term changes in trophic niche suggest the ecological impacts of pumpkinseed on recipient biota may be temporally dynamic. The patterns perceived in this study are unlikely to be driven only by methodological bias. Although samplesizes were generally small, this appears unlikely to have affected the results. For instance, population diet breadth was broader in 2003 and 2013 when sampling effort was lower. The lack of data on fish abundance and prey availability may also be considered a potential shortcoming. Fish abundance and prey availability could influence the trophic relations between pumpkinseed and co-occurring species and should thus be addressed in future studies.

Trophic patterns of both small and large pumpkinseed through time reflected a shift from specialization on chironomids during establishment to more generalized feeding during integration, with the inclusion in the diet of copepods followed by hemipterans and also ephemeropterans for large fish. This increase in the array of prey consumed by pumpkinseed 

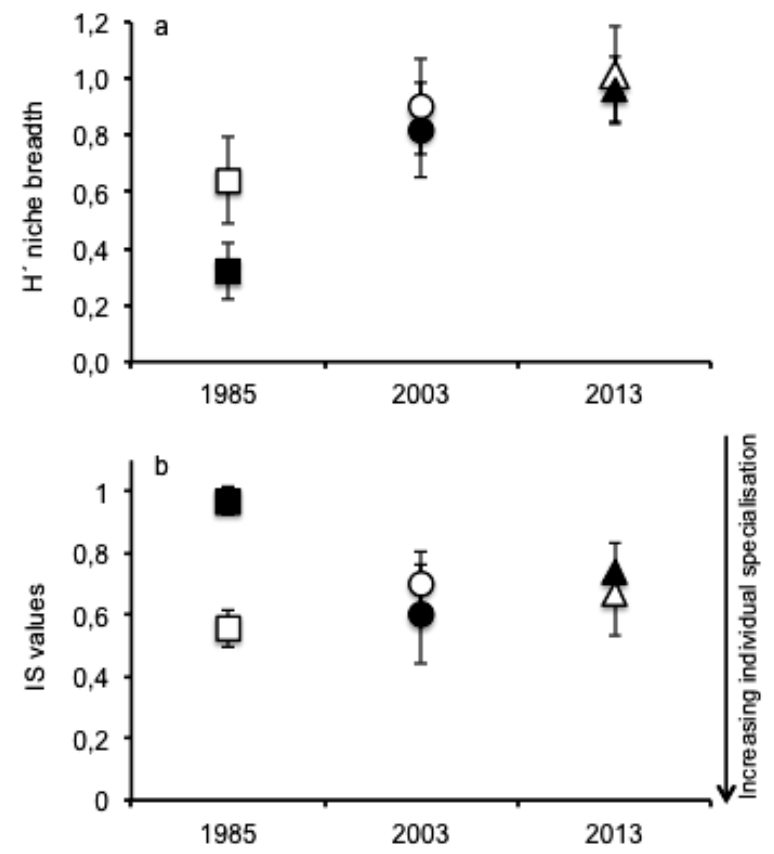

Fig. 2. Variation in (a) population diet breadth (Shannon-Wiener $\mathrm{H}^{\prime}$ index) and (b) individual diet specialization (IS index) for small (open symbols) and large (black symbols) pumpkinseed Lepomis gibbosus during the establishment (1985) and integration stages (2003 and 2013) of the invasion in the mainstem of the Guadiana river (Portugal). Error bars represent boot-strapped 95\% confidence intervals for each index.

may reflect an adaptive response to the recipient ecosystem (Strayer et al., 2006), with diet varying according to local prey availability and shifting to less exploited preys as it has been pointed for other introduced populations (Godinho et al., 1997b; Almeida et al., 2009). Some changes in the prey availability are likely to have occurred after 2001 , following the construction of a large reservoir located about $35 \mathrm{~km}$ upstream (Ribeiro and Collares-Pereira, 2010). Nevertheless, trophic patterns reflected the consumption of a higher diversity of preys confirming that plasticity may persist along the invasion process.

The increase in trophic niche size of pumpkinseed was associated with an increase in individual diet specialization in large fish which may result in reduced intra-specific competition (see Svanbäck and Persson, 2004) and thus facilitate the spread and integration of this invasive species. In the case of small fish, the degree of individual specialization remained similar over time although population diet breadth has also expanded across the invasion process.

Variation in biological traits may provide an important advantage to invasive species, allowing successful transitions throughout the invasion process and favoring integration into the recipient ecosystem (Bøhn et al., 2004; Feiner et al., 2012). Especially, high morphological change has been attributed to pumpkinseed (Yavno et al., 2014), which together with variability in trophic niche composition and size recorded herein may enable this species to cope with the novel environments. Pumpkinseed seemed to be able to increasingly use resources at different levels in the food web throughout the invasion pro- cess, suggesting that its impacts in recipient native communities may be temporally variable. Further research on long-term feeding of native species in relation to its abundance and prey availability is needed to clarify mechanisms behind resource use and the extent to which invasive species may affect the ecosystem structure and function.

Acknowledgements. The authors gratefully acknowledge the financial support of "Fundação para a Ciência e Tecnologia" (FCT - Portugal), through the postdoctoral fellowships that supported C. Gkenas (SFRH/BPD/84859/2012) and F. Ribeiro (SFRH/BPD/46761/2008), from the Programa Operacional Potencial Humano/Fundo Social Europeu (POPH/FSE). This work was supported by the strategic plan of MARE - Marine and Environmental Sciences Centre (UID/MAR/04292/2013). J. Cucherousset was supported by an "ERG Marie Curie" grant (PERG08-GA-2010- 276969) in the lab EDB, part of the French Laboratory of Excellence project "TULIP" (ANR-10-LABX-41; ANR-11-IDEX-0002-02).

\section{References}

Almeida, D., Almodóvar A., Nicola G.G. and Elvira B., 2009. Feeding tactics and body condition of two introduced populations of pumpkinseed Lepomis gibbosus: taking advantages of human disturbances? Ecol. Freshw. Fish, 18, 15-23.

Bhagat Y., Fox M.G. and Ferreira M.T., 2011. Trophic polymorphism in introduced pumpkinseed (Lepomis gibbosus) inhabiting Iberian reservoirs. Environ. Biol. Fish., 91, 203-217.

Bolnick D.I., Yang L.H., Fordyce J.A., Davis J.M. and Svanbäck R., 2002. Measuring individual-level resource specialization. Ecology 83, 2936-2941.

Bøhn T., Sandlund O., Amundsen P. and Primicerio R., 2004. Rapidly changing life-history during invasion. Oikos, 106, 138-150.

Clarke K.R. and Gorley R.N., 2006. PRIMER v6: User manual/tutorial, PRIMER-E, Plymouth, 192 p.

Colwell R.K. and Futuyma D.J., 1971. On the measurement of niche breadth and overlap. Ecology, 52, 567-576.

Domingos I., 1986. Contribuição para o estudo da biologia e ecologia de Lepomis gibbosus (Linnaeus, 1758). Licenciatura Thesis, Universidade de Lisboa, Lisboa, 255 p.

Feiner Z.S., Aday D.D. and Rice J.A., 2012. Phenotypic shifts in white perch life-history strategy across stages of invasion. Biol. Invasions, 14, 2315-2329.

Fox M.G. and Copp G.H., 2014. Old world versus new world: life-history alterations in a successful invader introduced across Europe. Oecologia, 174, 435-446.

García-Berthou E. and Moreno-Amich R., 2000. Food of introduced pumpkinseed sunfish: ontogenetic diet shift and seasonal variation. J. Fish Biol., 57, 29-40.

Godinho F.N., Ferreira M.T. and Cortes R.V., 1997a. Composition and spatial organization of fish assemblages in the lower Guadiana basin, southern Iberia. Ecol. Freshw. Fish, 6, 134-143.

Godinho F.N., Ferreira M.T. and Cortes R.V., 1997b. The environmental basis of diet variation in pumpkinseed sunfish, Lepomis gibbosus, and largemouth bass, Micropterus salmoides, along an Iberian river basin. Environ. Biol. Fish., 50, 105-115.

Grey J. and Jackson M.C., 2012. 'Leaves and Eats Shoots': direct Terrestrial Feeding Can Supplement Invasive Red Swamp Crayfish in Times of Need. PLoS One, 8, e42575.

Kolar C.S. and Lodge D.M., 2001. Progress in invasion biology: predicting invaders. Trends Ecol. Evol., 16, 199-204. 
Levins R. 1968. Evolution in Changing Environments. Princeton University Press, Princeton, NJ, USA, 120 p.

Magalhães M.F., 1993. Effects of season and body-size on the distribution and diet of the Iberian chub Leuciscus pyrenaicus in a lowland catchment. J. Fish Biol., 42, 875-888.

R Development Core Team, 2014. R: A language and environment for statistical computing. R Foundation for Statistical Computing, Vienna. http://www.R-project.org.

Ribeiro F. and Collares-Pereira M.J., 2010. Life-history variability of non-native centrarchids in regulated river systems of the lower River Guadiana drainage (south-west Iberian Peninsula). J. Fish Biol., 76, 522-537.

Ribeiro F., Orjuela R.L., Magalhães M.F. and Collares-Pereira M.J., 2007. Variability in feeding ecology of a South American cichlid: a reason for successful invasion in Mediterranean-type rivers? Ecol. Freshw. Fish, 16, 559-569.

Shea K. and Chesson P., 2002. Community ecology theory as a framework for biological invasions. Trends Ecol. Evol., 17, $170-176$.

Strayer D.L. 2012. Eight questions about invasions and ecosystem functioning. Ecol. Lett. 15, 1199-1210.
Strayer D.L., Eviner V.T., Jeschke J.M. and Pace M.L., 2006. Understanding the long-term effects of species invasions. Trends Ecol. Evol. 21, 645-651.

Svanbäck R. and Persson L., 2004. Individual diet specialization, niche width and population dynamics: implications for trophic polymorphisms. J. Anim. Ecol., 73, 973-982.

Tilberg C.V., Holway D.A., LeBrun E.G. and Suarez A.V., 2007. Trophic ecology of invasive Argentine ants in their native and introduced ranges. Proc. Natl. Acad. Sci. USA, 104, 20856-20861.

Tran T.N.Q., Jackson M.C., Sheath D., Verreycken H. and Britton J.R., 2015. Patterns of trophic niche divergence between invasive and native fishes in wild communities are predictable from mesocosm studies. J. Anim. Ecol., 84, 1071-1080.

Vázquez D.P., 2006. Exploring the relationship between niche breadth and invasion success. In: Cadotte M.W., McMahon S.M. and Fukami T. (eds.), Conceptual ecology and invasions biology, Springer, Dordrecht, 307-322.

Yavno S., Rooke, A.C., and Fox M.G. 2014. Morphological change and phenotypic plasticity in native and non-native pumpkinseed sunfish in response to competition. Naturwissenschaften, 101, 479-492.

Cite this article as: C. Gkenas, M.F. Magalhães, J. Cucherousset, I. Domingos, F. Ribeiro, 2016. Long term patterns in the late summer trophic niche of the invasive pumpkinseed sunfish Lepomis gibbosus. Knowl. Manag. Aquat. Ecosyst., 417, 19. 